\title{
The Influence of Transformational School Leadership on Teacher Efficacy in Malaysian Secondary School Teachers
}

\author{
Teh Pei Ling (Corresponding author) \\ University Putra Malaysia, Selangor, Malaysia \\ Zaidatol Akmaliah Lope Pihie \\ University Putra Malaysia, Selangor, Malaysia
}

Soaib Asimirin

University Putra Malaysia, Selangor, Malaysia

Foo Say Fooi

University Putra Malaysia, Selangor, Malaysia

Received: June 12, 2015 Accepted: July 15, 2015 Published: August 17, 2015

doi:10.5296/ijssr.v3i2.7794 URL: http://dx.doi.org/10.5296/ijssr.v3i2.7794

\begin{abstract}
This study provides an insight of the relationship between principals' transformational school leadership practices and teacher efficacy among Malaysian secondary school teachers. Data was gathered from teachers of secondary schools in the central region of Peninsular Malaysia. The self-administered questionnaires, totalling 160 copies were distributed to the respondents. Valid samples stood at 137 teachers, resulting in a response rate of 85.6 percent. The data was analysed using descriptive, correlation and multiple regression analyses to evaluate the relationship between transformational leadership practices and teacher efficacy. The analysis revealed a significant relationship between the dimensions in transformational school leadership and teacher efficacy. The findings concur with the studies done by Leithwood (1994) that there is a significant relationship between the dimensions of transformational
\end{abstract}


school leadership practices and teacher efficacy. These findings are also in line with past research (Kristine \& Hipp, 1997; Peagler, 2004; Ross, J. A, Gray, 2006) that the said transformational leadership contributes toward teachers' self-efficacy. Therefore, this study strengthens the findings by engaging in similar relationship.

Keywords: Transformational School Leadership, Teacher efficacy, Secondary school teachers

\section{Introduction}

Teachers educate great people. For generations, teachers play the vital roles in educating students in schools and their roles are significantly factored into students' learning outcomes in education (Dellinger, Bobbett, Olivier, \& Ellett, 2008).

Much effort has been put into motivating teachers in their career which would in turn churn out better and educated young generation. In all the stages of formal education, teachers are the front line people who educate and bring impact to the newer generation in a country. The roles of teacher are pertinent in ensuring the success of students in furthering their tertiary level education from their common primary and secondary school education. With the current Malaysian education system that is constantly introducing changes and reviews in education policies (Ministry of Education, 2011), school teachers are the vital people who will execute educational plans (Chan, 2008; Park, Henkin, \& Egley, 2005). Hence, teacher efficacy is pertinent as it affects greatly the students' learning outcomes (Caprara, Barbaranelli, Steca, \& Malone, 2006; Dellinger et al., 2008; Robinson, Lloyd, \& Rowe, 2008).

In relation to this, teachers who have higher self-efficacy will teach more effectively (Ross, J. A, Gray, 2006; Ware \& Kitsantas, 2007). Teacher efficacy research has been widely conducted in various education settings. The rise in transformational leadership style as an important determinant of teacher efficacy is evidently found in research (Nielsen, Yarker, Randall, \& Munir, 2009; Wahlstrom \& Louis, 2008). A cornucopia of information has been written about the philosophy of Transformational School Leadership and its impact for short and long term competitive success. Over the past two decades, Malaysian schools have experienced dramatic changes in education arena with education policies changes and new implementations. To stay competitive in this education platform, the Ministry of Education has been sending pre-promoted principals to Principalship courses for training in Institute Aminuddin Baki (2002) IAB. In response to these education changes and challenges, many schools have joined the school improvement initiatives and implemented various school improvements as a means to enhance school competitiveness.

However, there is a limited study of school principal leadership's practice research studies to understand the current school practices and teacher efficacy on their school management journey towards achieving the national wide education system policy, especially to achieve the 11 shifts in the Malaysia Education Blueprint (Malaysia Education Blueprint 2013-2025, 2012). Therefore, an effective management of Transformational school leadership towards boosting teacher efficacy is the main focus of an effective principal. Fullan (2001) projected evidences that change takes place with effective principal. School principal should develop 
deeper understanding of the transformational school leadership practices and its impact on teacher efficacy. This is because teacher efficacy contributes to students and school achievement as highly efficacious teachers worker harder, use various strategies that stimulate student learning, attend more closely to low ability student needs, and modify students' ability perceptions (Protheroe, 2008; Ross, J. A, Gray, 2006). Hence, teacher efficacy is imperative in ensuring fruitful student learning outcomes in a classroom. With the centralized school education system in Malaysia, principal's leadership does influence directly or indirectly on teachers' efficacy. However, evidence to this relationship between transformational leadership and teacher efficacy has been inconsistent (Horn-turpin, 2009; Kristine \& Hipp, 1997). So, this study aspires to uncover an insight of school principals, evaluating the relationship between transformational school leadership and teacher efficacy.

\section{Literature Review}

\subsection{Transformational School Leadership}

In leadership literature, transformational leadership is linked to the promotion of change and improvement in schools (Kong, Leithwood, \& Jantzi, 2002; Leithwood \& Jantzi, 2008; Leithwood \& Jantzi, 2006; Leithwood, 2007). Change and improvement in schools are often associated with how the leader leads his or her subordinates. The famous transformational leadership gurus, James MacGregor Burns, Bernard M. Bass, Bruce J. Avolio, and Kenneth Leithwood (Stewart, 2006) dedicated their research on the concept and evolution of transformational leadership.

Transformational leadership is seen to be sensitive to school improvement in promoting positive school outcomes (Leithwood \& Jantzi, 2005; Sun \& Leithwood, 2012). Principal who adopts transformational leadership practices motivates teachers to rise above their personal expectations and help create common school vision and missions. According to Ross and Gray (2006), the "essence of transformational leadership is dedication to fostering the growth of organizational members and enhancing their commitment by elevating their goals".

\subsection{Teacher Efficacy}

Teacher efficacy is the teacher's confidence level in their ability to promote student learning (Hoy, 2000). It is reported that teacher efficacy lies under the theoretical concept of self-efficacy. Bandura (1986, 2006) defined perceived self-efficacy as "beliefs in one's capabilities to organize and execute courses of action required in managing prospective situations". Similarly, Ross and Gray (2006) also defined teacher efficacy as a set of personal efficacy beliefs that refer to the specific domain of the teacher's professional behaviour. It deals with how the teachers feel and the teaching actions that is translated into students learning outcomes. As noted earlier, teachers can feel efficacious in one school context and quite inefficacious in another. The level of perceived competence to meet the demands of a particular teaching task influence the performance in the school.

Besides, teacher efficacy consistently predicts willingness to try out new teaching ideas (Ross, 2004). High expectations of success motivate classroom experimentation because teachers anticipate they will be able to achieve the benefits of innovation and overcome obstacles that 
might arise. These teachers are willing to try out new things for the benefits of the students. Tschnanen-moran \& Hoy (2001) presented three components of teacher efficacy: (1) Efficacy in student engagement, (2) Efficacy in instructional strategies and (3) Efficacy in classroom management. In their research, efficacy in classroom measures teachers' confidence in managing the classroom, house-keeping and other classroom related issues. On the other hand, efficacy in instructional deals with how the teachers instruct students in the process of teaching where else the efficacy in student engagement deals with how the teacher tries to engage the students in their learning. However, in this study, the three components have been computed to one general teacher efficacy.

\subsection{Relationships between Transformational School Leadership and Teacher Efficacy}

A research framework is used as a means to explore the relationships between transformational school leadership and teacher efficacy in Malaysia secondary schools. Principals' transformational school leadership practices form the independent variables and teacher efficacy is the dependent variable in this study. The proposed model reinforces the need for school management to recognize specific dimensions that affect teacher efficacy ultimately. Transformational leadership theory and Bandura's Social Cognitive Theory serve as the anchors in developing the conceptual framework.

Table 2.1 The conceptual framework

\begin{tabular}{|c|c|}
\hline Transformational School Leadership & Teacher Efficacy \\
\hline (i) Develops a shared vision, & (i) Efficacy in student engagement, \\
\hline (ii) School goals & (ii) Efficacy in instructional strategies \\
\hline (iii) High expectation & (iii) Efficacy in classroom management. \\
\hline (iv) Moral Behaviour & \\
\hline (v) Individualised support & \\
\hline (vi) Intellectual Stimulation & \\
\hline (vii) School culture & \\
\hline (viii) Collaboration. & \\
\hline
\end{tabular}

Table 2.1 presents the conceptual framework of the study with teacher efficacy as the dependent variable and the remaining eight constructs in Leithwood's (1994) transformational school leadership as independent variables.

School teachers who work under the leadership of a principal and their level of teaching can depend on past experiences with different leadership styles. Principals can help develop a sense of efficacy for every teacher and for the entire school by motivating them (Protheroe, 2008). Hence, transformational leadership affects teacher efficacy. The efficacy in a teacher will help boost the level of confidence thus improving the student learning outcomes. School principals who practise transformational school leadership tend to influence teacher efficacy by boosting the confidence in teachers to think critically and bounded by the goals in school and the ministry of education. Thus, transformational school leadership, with its dimensions, 
affects teacher efficacy.

\section{Research Design}

The targeted population of this study was teachers teaching in the three states in the central region in Malaysia secondary schools. Permissions and approvals were sought from the Educational Planning, Research and Development Department (EPRD), and the Malaysian Ministry of Education to conduct this study in the selected secondary schools. The questionnaires were distributed to 160 teachers and 150 questionnaires were returned of which 137 were valid for data analysis, yielding a respond rate of about 85.6 percent. Respondents were told that the questionnaires were collected mainly for research purposes which are likely to result in less self-enhancement than when data are collected for administrative purposes (Ary, Jacobs, \& Sorensen, 2006).

The research instrument in this study consists of two major sections. The first section comprises eight dimensions measuring transformational school leadership practices and the second section comprises three dimensions that measure teacher efficacy of the selected secondary school teachers in the central region of the Malaysian schools. Both transformational school leadership questionnaires and teacher efficacy were adapted from the western countries. So, to cater to the local teachers' language competency, the questionnaires were translated using back-to-back method. English language was first translated into Malay language and it was then translated back into English again to check on the questionnaires.

Leithwood's transformational school leadership instruments with eight dimensions were adapted in this study. The eight dimensions are shared vision, school goals, high expectation, model behaviour, individual support, intellectual stimulation, culture and collaborative structures. The instruments used had a six-point likert scale, representing a range of responses from strongly disagree to strongly agree.

The teacher efficacy questionnaires (TSES) were used to investigate the level of teacher efficacy. It has three components of teacher efficacy: (i) Efficacy in student engagement, (ii) Efficacy in instructional strategies \& (iii) Efficacy in classroom management. Subject measures for efficacy were assessed by five-point interval scale. The respondents were required to indicate their degree of agreement or disagreement ranging from: 1 = Strongly disagree $(\mathrm{SD})$ to $5=$ Strongly agree $(\mathrm{SA})$.

The collected data were analysed using SPSS Version 20.0 program for windows for the descriptive and inferential statistics. Descriptive analysis, like mean scores and standard deviation, were used to examine the findings. Inferential statistics such as correlation analysis was used to examine the strength and linear relation direction between two variables (Pallant, 2010). Next, multiple regression analysis was used to test the research question for significant relationship between transformational school leadership and teacher efficacy. 


\section{N Macrothink

\section{Findings and Discussion}

\subsection{Factor Analysis and Scale Reliabilities}

To examine the reliability of the instruments, Cronbach's Alpha was calculated to measure the internal consistency reliability of transformational leadership and teacher efficacy. The results showed the internal consistency reliability was above 0.7 after excluding a few items in the instruments that were below the said factor loading of 0.6. All the scales had acceptable reliability as factor loading above 0.6 is acceptable.

Next, to examine its validity, the research instrument was analysed using factor analysis. The Kaiser-Meyer-Olkin (KMO) values measure of sampling adequacy were well above the acceptable level of 0.6 and thus factorability was assumed (Coakes, Steed, \& Dzidic, 2006).

The high Cronbach's Alpha values ranged from 0.723 to 0.954 . It indicated that the items used for measuring transformational leadership and teacher efficacy were reliable. On the other hand, KMO (Kaiser-Meyer-Olkin) values which ranged from 0.617 to 0.868 showed that sampling adequacy was far greater than 0.6 indicating that the instrument was significant (Pallant, 2010). The statistical values for skewness and kurtosis recorded between -1.96 to +1.96 and thus the data were of normal distribution and were suitable for data analysis (Pallant, 2010). The skewness ranges from 0.036 to 0.612; and for kurtosis, the range is from 0.054 to 0.671 . Factor analysis and scale reliabilities, as well as descriptive statistics analyses were initially undertaken for the study variables.

\subsection{Profiles of Respondents}

There were $113(82.50 \%)$ female and only 24 (17.50\%) male respondents. Overall, 1.46\% teachers were aged less than 25 years old, $16.79 \%$ were between $26-30$ years old, $18.98 \%$ were between $31-35$ years old, 36-40 years old stood at $24.82 \%$ and $10.95 \%$ for $41-45$ years old. Participants from 46-50 years old stood at $27(19.70 \%)$ and the remaining $7.3 \%$ were aged over 50 years old. From these results of age group, it is known that the present data were mainly collected from middle-aged teachers. Similarly, $122(89.1 \%)$ of the respondents had achieved at least a bachelor qualification. Out of all the survey participants, $75.91 \%$ have worked more than 5 years in their current school with only $24.09 \%$ have worked less than 5 years for the length of services. The profiles of the survey respondents are summarized in Table 4.1. 
Table 4.1 Profiles of the survey respondents. $\mathrm{N}=137$

\begin{tabular}{|c|c|c|c|c|}
\hline Profile & No of respondents & Category & Count & Percentage (\%) \\
\hline \multirow[t]{2}{*}{ Gender } & 137 & Male & 24 & 17.50 \\
\hline & & Female & 113 & 82.50 \\
\hline \multirow[t]{7}{*}{ Age } & 137 & $<25$ yrs old & 2 & 1.46 \\
\hline & & $26-30$ yrs old & 23 & 16.79 \\
\hline & & $31-35$ yrs old & 26 & 18.98 \\
\hline & & $36-40$ yrs old & 34 & 24.82 \\
\hline & & $41-45$ yrs old & 15 & 10.95 \\
\hline & & $46-50$ yrs old & 27 & 19.70 \\
\hline & & $>51$ yrs old & 10 & 7.30 \\
\hline \multirow[t]{3}{*}{ Race } & 137 & Malay & 109 & 79.6 \\
\hline & & Chinese & 19 & 13.9 \\
\hline & & Indian & 9 & 6.6 \\
\hline \multirow[t]{2}{*}{ Qualification } & 137 & Bachelor degree & 122 & 89.10 \\
\hline & & Master degree & 15 & 10.90 \\
\hline \multirow[t]{7}{*}{ Length of services } & 137 & $1-5 \mathrm{yrs}$ & 33 & 24.09 \\
\hline & & $6-10 \mathrm{yrs}$ & 31 & 22.63 \\
\hline & & $11-15 \mathrm{yrs}$ & 23 & 16.79 \\
\hline & & $16-20 \mathrm{yrs}$ & 14 & 10.22 \\
\hline & & $21-25 \mathrm{yrs}$ & 23 & 16.79 \\
\hline & & $26-30 \mathrm{yrs}$ & 9 & 6.57 \\
\hline & & $31-35 \mathrm{yrs}$ & 4 & 2.91 \\
\hline
\end{tabular}

\subsection{Descriptive Analysis}

The various mean scores of the dimensions were computed and analysed for estimating the level of transformational school leadership practices perceived by the respondents. The results are presented in Table 4.2. An overall mean score of 4.30 with a standard deviation of 0.551 indicated that the Malaysian schools generally have a positive level of transformational school leadership implementation. This is due to the directive from the Ministry of Education on education policy changes and improvement, particularly to stay on par with the Malaysian Education Blueprint (Malaysia Education Blueprint 2013-2025, 2012). This score is at the upper middle end of the six-point Likert scales, where 6 represents the maximum positive evaluation and 1 the maximum negative evaluation.

In this study, the findings indicated the score for shared vision was at a moderate high level $(M=4.54, S D=0.670)$ based on a scale of one to six. It means that principals shared their school vision to the teachers. Additionally, the study also showed that school goals score that was high $(M=4.52, S D=0.666)$, it indicates that principals project medium high influence on school goals. The mean score was the highest for high expectation, $(M=4.80, S D=$ 0.688). This suggests that the principals have high expectation on the teachers' performance. The least level of mean is the individual support implying that the teachers do not think the 
principals have high level of individual support to the teachers. Finally the teacher efficacy stands at $\mathrm{M}=3.83, \mathrm{SD}=0.381$ which indicates high teacher efficacy.

The findings of the means and standard deviation analysis are as in Table 4.2 below.

Table 4.2. Means and SD for the main and sub-constructs

\begin{tabular}{lcc}
\hline \multicolumn{1}{c}{ Dimensions } & Mean & Std. Deviation \\
\hline Total Transformational School Leadership & 4.30 & 0.551 \\
- Shared vision & 4.54 & 0.670 \\
- School goal & 4.52 & 0.666 \\
- High Expectation & 4.80 & 0.688 \\
- Moral behaviour & 4.34 & 0.557 \\
- Individual Support & 4.04 & 0.683 \\
- Intellectual Stimulation & 4.52 & 0.611 \\
- School Culture & 4.23 & 0.569 \\
- Collaboration Structures & 4.29 & 0.656 \\
Total Teacher efficacy & 3.83 & 0.381 \\
\hline
\end{tabular}

\subsection{Correlation Analysis}

The relationship between perceived transformational school leadership and teacher efficacy was investigated using Pearson Product-moment correlation coefficient. Preliminary analyses were performed to ensure no violation of the assumptions of normality, linearity and homoscedasticity. The Pearson Product-Moment statistical correlation analysis method was used to determine the relationship between independent variables and dependent variable. The relationship was determined through the relationship between the mean score of principals' transformational leadership practices (Shared Vision, School Goals, High expectation, Model Behaviour, Individual Support, Intellectual Stimulation, Culture, Collaborative Structures) with the mean score of the teacher efficacy.

Table 4.3. Pearson correlations analysis between Transformational Leadership and Teacher efficacy

\begin{tabular}{llll}
\hline Independent Variables & Teachers' Efficacy & & Strength of relationship \\
\hline School Goal & .388 & $.000^{*}$ & Medium \\
Model Behaviour & .379 & $.000^{*}$ & Medium \\
Intellectual Stimulation & .357 & $.000^{*}$ & Medium \\
High expectation & .349 & $.000^{*}$ & Medium \\
Shared Vision & .329 & $.000^{*}$ & Medium \\
Collaborative Structures & .293 & $.000^{*}$ & Small \\
School Culture & .276 & $.001^{*}$ & Small \\
Individual Support & .168 & $.025^{*}$ & Small \\
\hline
\end{tabular}

*correlation significance at .05. 


\section{Ml Macrothink}

Using Cohen (1988, pp.79-81 in Pallant, 2010) rules of thumb, the strength of correlation ranging $\mathrm{r}=.1-$ to .29 is small, $\mathrm{r}=.30$ to .49 is medium and $\mathrm{r}=.50$ to 1.0 is large. Based on Table 4.3 above, the findings indicate that principals who emphasised on school goals have a significant relationship with teacher efficacy but the strength of relationship is medium ( $r$ $=.388, p=.000$ ). Thus, this result proposes that there is a positive correlation with coefficient value of .388 indicating that the higher the principals' share the school goals with the teachers, the greater the teacher efficacy in secondary school teachers.

The second highest strength of relationship is principals' model behaviour which stood at $\mathrm{r}=.379, \mathrm{p}=.000$, it has a medium strength of relationship too. This is followed by Intellectual stimulation $(\mathrm{r}=.357, \mathrm{p}=.000)$, high expectation $(\mathrm{r}=.349, \mathrm{p}=.000)$ and shared vision $(\mathrm{r}=.329$, $\mathrm{p}=.000)$.

The remaining two dimensions, collaborative structures and school culture both have small strength of relationship and they stood at $\mathrm{r}=.293, \mathrm{p}=.000$ and $\mathrm{r}=.276, \mathrm{p}=.001$ respectively.

Generally, the inter-correlations among the dimensions of transformational school leadership styles and teacher efficacy have demonstrated a medium strength of correlation. The school culture and collaborative structures have small strength of correlations.

\subsection{Multiple Regression Analysis}

Multiple regression analyses were carried out to test the hypothesized relationships between the dimensions of Principals' transformational leadership practices and teacher efficacy and to determine the extent of Transformational Leadership determinants, using the eight dimensions could predict teacher's efficacy among secondary school teachers, the standard multiple regression analysis was used.

The standard multiple regression analysis shows that transformational school leadership practices are significant predictors for Malaysian secondary school teachers' efficacy, $\mathrm{R}^{2}$ $=.226, \mathrm{R}^{2} \mathrm{adj}=.177, \mathrm{~F}(8,128)=4.660, \mathrm{p}<.05$. The Adjusted $R^{2}$ value of .177 shows that transformational leadership practices only predict $17.7 \%$ of teacher efficacy in secondary school teachers.

Based on the analysis table, it is depicted that school goals $(\beta=.334, \mathrm{p}<.05)$, model behaviour $(\beta=.349, \mathrm{p}<.05)$ and individual support $(\beta=.416, \mathrm{p}<.05)$ contribute significantly to teacher efficacy in teaching. On the other hand, the other dimensions, shared vision, high expectation, intellectual stimulation, school culture and collaborative structures do not contribute significantly to teacher's efficacy.

The findings of the Standard Multiple Regression Analysis are shown in Table 4.4. 
Table 4.4. Result of standard multiple regression analysis

\begin{tabular}{llll}
\hline Predictors & $\beta$ & $t$ & $p$ \\
\hline Shared Vision & .120 & 0.6 & .53 \\
School Goals & $.334^{*}$ & 2.12 & .04 \\
High expectation & .012 & 0.08 & .94 \\
Model Behaviour & $.349^{*}$ & 2.05 & .04 \\
Individual Support & $.416^{*}$ & 2.84 & .005 \\
Intellectual Stimulation & .022 & 0.11 & .92 \\
School Culture & .030 & 0.17 & .86 \\
Collaborative Structures & -.059 & -.392 & .69 \\
\hline
\end{tabular}

$\mathrm{R}=.475, \mathrm{R}^{2}=.226, R^{2}$ (adjusted) $=.177$

$* p<.05$

\section{Conclusion and Implications}

As a whole, this paper provides an insight of the relationship between transformational school leadership and teacher efficacy experienced by Malaysian secondary school teachers. Transformational Leadership practices have relative impacts on teacher efficacy towards their schools (Horn-turpin, 2009; K. A. Leithwood, 1991; Ross \& Gray, 2006). The findings support potential implications for school top management to review their leadership practices in school. It seeks to contribute in advancing the school leadership literature with a better understanding of the multidimensionality of transformational leadership practices and its association with teacher efficacy that would facilitate more quality teaching and learning in productive classrooms in Malaysia. In another words, principal will know which factor to focus on in boosting teacher efficacy in their respective schools.

\section{Limitations and Future Research}

Research limitations are unavoidable, therefore these limitations should be considered for future research. Firstly, the data was obtained from Malaysia secondary school teachers in cross-sectional method rather than longitudinal method, the latter method will provide more profound findings. Thus, due to the limitation of cross-sectional method that was used in this study, the issue of common method variance (CMV) is present and it should be dealt with in the future research. This is to reduce the probability of unreliable data being used and the research findings that might hold a certain degree of biasness.

Secondly, the findings of this study are based on the use of self-administrated questionnaires from the teachers, which may be affected by response biases. It is difficult to determine through questionnaires whether teachers' perceptions of transformational leadership and teacher efficacy are pervasive or apparent. Therefore, interviews are suggested to be conducted for a few selected teachers. The informative data will strengthen the research findings. Finally, since the respondents were randomly selected from schools in each selected state, the results reported may not be generalized for other cultural situations. Thus, future research may need to collect data from other states and region, in order to have a more insight 
on transformational leadership influencing teacher efficacy in Malaysia. Perhaps moderating variables such as the level of academic qualification and years of experience may project some interesting insights on the variances of transformational school leadership that explain teacher efficacy.

\section{References}

Ary, D., Jacobs, L. C., \& Sorensen, C. (2006). Introduction to Research in Education (8th ed.). Belmont: Wadsworth Cengage Learning.

Bandura, A. (1986). Social foundations of thought and action. New Jersey: Prentice-Hall.

Bandura, A. (2006). Guide for constructing self-efficacy scales. In Self-Efficacy Beliefs of adolescents (pp. 307-337).

Caprara, G. V., Barbaranelli, C., Steca, P., \& Malone, P. S. (2006). Teachers' self-efficacy beliefs as determinants of job satisfaction and students' academic achievement: A study at the school level. Journal of School Psychology, 44(6), 473-490. http://dx.doi.org/10.1016/j.jsp.2006.09.001

Chan, W. et al. (2008). Organizational and Personal Predictors of Teacher Commitment: The Mediating Role of Teacher Efficacy and Identification with school. American Educational Research Journal, 45(3), 597-630. http://dx.doi.org/10.3102/0002831208318259

Dellinger, A. B., Bobbett, J. J., Olivier, D. F., \& Ellett, C. D. (2008). Measuring teachers' self-efficacy beliefs: Development and use of the TEBS-Self. Teaching and Teacher Education, 24, 751-766. http://dx.doi.org/10.1016/j.tate.2007.02.010

Horn-turpin, F. D. (2009). A study examining the effects of transformational leadership behaviours on the factors of teaching efficacy, job satisfaction and organisational commitment as perceived by special education teachers. Thesis by Virgina Polytechnic Institute and State University.

Hoy, A. W. (2000). Changes in teacher efficacy During the early years of teaching. In Qualitative and Quantitative Approaches to Examining Efficacy in Teaching and Learning (pp. 1-26).

Kristine, A., \& Hipp, K. A. (1997). Documenting the effects of Transformational Leadership Behavior on Teacher Efficacy.

Leithwood, K. (2007). What we know about Educational Leadership. In C. W. \& P. K. J. M. Berger (Ed.), Intelligent Leadership (pp. 41-66). http://dx.doi.org/10.1007/978-1-4020-6022-9_4

Leithwood, K. A. (1992). The Move Toward Transformational Leadership, 8-12.

Leithwood, K., \& Jantzi, D. (2005). A Review of Transformational School Leadership Research 1996-2005. Leadership and Policy in Schools, 4(3), 177-199. http://dx.doi.org/10.1080/15700760500244769 
Leithwood, K., \& Jantzi, D. (2006). Transformational school leadership for large-scale reform: Effects on students, teachers, and their classroom practices. School Effectiveness and School Improvement, 17(2), 201-227. http://dx.doi.org/10.1080/09243450600565829

Leithwood, K., \& Jantzi, D. (2008). Linking Leadership to Student Learning: The Contributions of Leader Efficacy. Educational Administration Quarterly, 44(4), 496-528. http://dx.doi.org/10.1177/0013161X08321501

Leithwood, K., \& Jantzi, D. (2010). Improvement: An International Journal of Research , Policy and Practice Leadership Effects : A Replication, (November 2013), 37-41.

Malaysia Education Blueprint 2013-2025. (2012). Putrajaya.

Ministry of Education. (2011). Pelan strategik interim 2011-2020. Ministry of Education. Retrieved from www.moe.gov.my/bppdp

Nielsen, K., Yarker, J., Randall, R., \& Munir, F. (2009). The mediating effects of team and self-efficacy on the relationship between transformational leadership, and job satisfaction and psychological well-being in healthcare professionals: a cross-sectional questionnaire survey. International Journal of Nursing Studies, 46(9), 1236-44. http://dx.doi.org/10.1016/j.ijnurstu.2009.03.001

Pallant, J. (2010). SPSS: Survival Manual (4th ed.). Berkhire: Open University Press.

Park, S., Henkin, A. B., \& Egley, R. (2005). Teacher team commitment, teamwork and trust: exploring associations. Journal of Educational Administration, 43(5), 462-479. http://dx.doi.org/10.1108/09578230510615233

Peagler, P. L. (2004). An examination of teacher efficacy and transformational leadership behaviors of principals in urban middle schools. Dissertation Abstracts International. A, The Humanities and Social Sciences. Retrieved from http://search.ebscohost.com/login.aspx?direct=trueunddb=psyhundAN=2004-99011-043unds ite= $=$ host-live

Protheroe, N. (2008). What Is It and Does It Matter? Teacher Efficacy:

Robinson, V. M. J., Lloyd, C. a., \& Rowe, K. J. (2008). The Impact of Leadership on Student Outcomes: An Analysis of the Differential Effects of Leadership Types. Educational Administration Quarterly, 44(5), 635-674. http://dx.doi.org/10.1177/0013161X08321509

Ross, J. A. (2004). Transformational Leaderhip and Teacher Commitment to Organizational Values: The Mediating Effects of Collective Teacher Efficacy.

Ross, J. A., \& Gray, P. (2004). Transformational leadership and teacher commitment to organizational values: The mediating effects of collective teacher efficacy. In Transformational Leadership and Collective Teacher Efficacy (Vol. 17, pp. 179-199). http://dx.doi.org/10.1080/09243450600565795

Ross, J. A, Gray, P. (2006). Transformational leadership, teacher commitment, and teacher efficacy. 


\section{Macrothink \\ International Journal of Social Science Research \\ ISSN 2327-5510 2015, Vol. 3, No. 2}

Stewart, J. (2006). Instructional and Transformational Leadership: Burns, Bass and Leithwoood, 1-29.

Sun, J., \& Leithwood, K. (2012). Leadership and Policy in Schools Transformational School Leadership Effects on Student Achievement. Leadership and Policy in Schools, 11(4), 418-451. http://dx.doi.org/10.1080/15700763.2012.681001

Wahlstrom, K. L., \& Louis, K. S. (2008). How Teachers Experience Principal Leadership: The Roles of Professional Community, Trust, Efficacy, and Shared Responsibility. Educational Administration Quarterly, 44(4), 458-495. http://dx.doi.org/10.1177/0013161X08321502

Ware, H., \& Kitsantas, A. (2007). Teacher and Collective Efficacy Beliefs as Predictors of. The Journal of Educational Research, 100, 303-311. http://dx.doi.org/10.3200/JOER.100.5.303-310

Yu, H., Leithwood, K., \& Jantzi, D. (2002). The effects of transformational leadership on teachers ' commitment to change in Hong Kong. Journal of Educational Administration, 40(4), 368-389. http://dx.doi.org/10.1108/09578230210433436

\section{Copyright Disclaimer}

Copyright for this article is retained by the author(s), with first publication rights granted to the journal.

This is an open-access article distributed under the terms and conditions of the Creative Commons Attribution license (http://creativecommons.org/licenses/by/3.0/). 